\title{
LAMA/LABA vs ICS/LABA in the treatment of COPD in Japan based on the disease phenotypes
}

\author{
This article was published in the following Dove Press journal: \\ International Journal of COPD \\ 10 June 2015 \\ Number of times this article has been viewed
}

\author{
Nobuyuki Hizawa \\ Department of Pulmonary Medicine, \\ Faculty of Medicine, University \\ of Tsukuba, Ibaraki, Japan
}

\begin{abstract}
In the combined use of bronchodilators of different classes, ie, long-acting $\beta_{2}$-agonists (LABAs) and long-acting muscarinic antagonists (LAMAs), bronchodilation is obtained both directly, through LABA-mediated stimulation of $\beta_{2}$-adrenergic receptors, and indirectly, through LAMA-mediated inhibition of acetylcholine action at muscarinic receptors. The clinical trial data for LABAs/LAMAs in the treatment of chronic obstructive pulmonary disease (COPD) continue to be promising, and these combinations will provide the convenience of delivering the two major bronchodilator classes, recommended as first-line maintenance options in COPD treatment guidelines. COPD is a complex condition that has pulmonary and extrapulmonary manifestations. These clinical manifestations are highly variable, and several are associated with different responses to currently available therapies. The concept of a COPD phenotype is rapidly evolving from one focusing on the clinical characteristics to one linking the underlying biology to the phenotype of the disease. Identification of the peculiarities of the different COPD phenotypes will permit us to implement a more personalized treatment in which the patient's characteristics, together with his or her genotype, will be key to choosing the best treatment option. At present in Japan, fixed combinations of inhaled corticosteroids (ICSs) and LABAs are frequently prescribed in the earlier stages of COPD. However, ICSs increase the risk of pneumonia. Notably, $10 \%-30 \%$ of patients with COPD with or without a history of asthma have persistent circulating and airway eosinophilia associated with an increased risk of exacerbations and sensitivity to steroids. Thus, sputum or blood eosinophil counts might identify a subpopulation in which ICSs could have potentially deleterious effects as well as a subpopulation that benefits from ICSs. In this review, I propose one plausible approach to position ICSs and LABAs/LAMAs in clinical practice, based on both the extent of airflow obstruction and the presence of an asthma component or airway eosinophilic inflammation. This approach is a tentative move toward personalized treatment for COPD patients, and with progress in knowledge and developments in physiology, lung imaging, medical biology, and genetics, identification of COPD phenotypes that provide prognostic and therapeutic information that can affect clinically meaningful outcomes is an urgent medical need.
\end{abstract}

Keywords: COPD phenotype, LAMA/LABA combination, ICS

\section{LAMA/LABA in the treatment of COPD}

Two key classes of bronchodilators have been developed in chronic obstructive pulmonary disease (COPD): $\beta_{2}$-agonists and muscarinic antagonists. Long-acting bronchodilators, such as tiotropium, formoterol, and salmeterol, are proven to provide long-term improvements in lung function and quality of life and preventing exacerbations in patients with COPD. ${ }^{1-3}$ Long-acting bronchodilators also reduce lung hyperinflation and dyspnea and increase exercise endurance., ${ }^{4,5}$

Airway smooth muscle relaxation (leading to bronchodilation) can be achieved via two main routes: inhibition of acetylcholine signaling via muscarinic $\mathrm{M}_{3}$ receptors
Correspondence: Nobuyuki Hizawa Department of Pulmonary Medicine, Faculty of Medicine, University of Tsukuba, Ibaraki 305-8575, Japan Emailnhizawa@md.tsukuba.ac.jp submit your manuscript $\mid$ www.dovepress.com

Dovepress

http://dx.doi.org// 0.2147/COPD.S72858
International Journal of COPD 2015:10 1093-II02 
on airway smooth muscle with a muscarinic antagonist or stimulation of $\beta_{2}$-adrenoceptors with a $\beta_{2}$-agonist. ${ }^{6}$ The interaction between the two systems has yet to be fully elucidated; however, $\beta_{2}$-agonists can amplify the bronchial smooth muscle relaxation directly induced by muscarinic antagonists by decreasing the release of acetylcholine via modulation of cholinergic neurotransmission. Additionally, in preclinical models, muscarinic antagonists have been demonstrated to augment $\beta_{2}$-agonist-stimulated bronchodilation by reducing the bronchoconstrictor effects of acetylcholine. Theoretically, targeting these two mechanisms of bronchoconstriction has the potential to maximize the bronchodilator response without increasing the dose of either component and would help to overcome the inter- and intrapatient variability in response to individual agents seen in COPD.

The regional distribution and relative proportion of muscarinic acetylcholine receptor ( $\mathrm{mAChR}$ ) and $\beta$-adrenoceptor subtypes were evaluated in the human bronchus and lung parenchyma. ${ }^{7}$ The $\mathrm{M}_{3}$ subtype predominantly occurred in the bronchus, but the density decreased from the segmental to subsegmental bronchus and was absent in the lung parenchyma. $\beta_{2}$-adrenoceptors were increased along the airways, and their densities in the subsegmental bronchus and lung parenchyma were approximately twofold higher than those of $\mathrm{mAChRs}$ in the same region. These differential distributions of the receptors may also underlie the increased efficacy of combined usage of long-acting $\beta_{2}$-agonists (LABAs) and long-acting muscarinic antagonists (LAMAs) in patients with COPD. A study conducted on airways of patients without histories of chronic airway diseases also suggested that combining LABA and LAMA in the treatment of COPD might have a rationale by providing synergistic benefit on airway smooth muscle relaxation of both the medium and the small human airways. ${ }^{8}$

These proposed pharmacologic interactions of LAMA and LABA are supported by clinical evidence suggesting that improvements in lung function (forced expiratory volume in 1 second; $\mathrm{FEV}_{1}$ ) are significantly greater with combinations of LABAs and LAMAs than with individual components ${ }^{3,9-11}$ and that such improvements are maintained in the long term. ${ }^{12,13}$ These studies also indicate that LAMA/LABA combinations are effective at improving patient-centered outcomes such as symptoms, health status, and the need for daytime rescue medication when compared with monotherapy. ${ }^{3,9,10}$ Changes in $\mathrm{FEV}_{1}$ following bronchodilator therapy can be small; however, the bronchodilator response in COPD patients is secondary to changes that involve static lung volumes reflected by residual volume and functional residual capacity rather than flow parameters ${ }^{14}$ and the accompanying larger change in lung volume, which contributes toward reduction in perceived breathlessness. ${ }^{15}$ In addition, bronchodilation may also influence smoking-induced remodeling of the small airways, which involves mucosal tissue changes, fiber types and/or fibrosis, pulmonary and systemic inflammation, lung vascular remodeling, and angiogenesis. ${ }^{16}$

Long-acting bronchodilators can reduce the rate of exacerbations, partly owing to a reduction in pulmonary hyperinflation and a resetting of the lung function dynamics. ${ }^{17}$ In the Withdrawal of Inhaled Steroids during Optimized Bronchodilator Management (WISDOM) study, Magnussen et $\mathrm{al}^{18}$ reported that the withdrawal of inhaled corticosteroids (ICSs) had no significant effect on exacerbations in patients with severe COPD. This result may suggest the presence of a subgroup of COPD patients who do not require ICSs even though they have severe airflow obstruction and frequent exacerbations. Future studies will examine which groups of patients might benefit from dual bronchodilation, along with the benefits of using this approach as the initial maintenance therapy.

Two fixed-dose combination inhalers (Ultibro ${ }^{\circledR}$, Novartis International AG, Basel, Switzerland and Anoro ${ }^{\mathrm{TM}}$, GlaxoSmithKline plc, London, UK) consisting of a LABA and a LAMA are currently available in Japan. Ultibro, an indacaterol/glycopyrronium combination, is the first commercial medication in Japan to combine once-daily LAMA and LABA. Anoro, an umeclidinium/vilanterol combination, is the first once-daily LAMA/LABA combination product to be approved in the United States. Both combinations take effect much faster than tiotropium and have mild side effects, particularly when compared with corticosteroid medications. In the near future, fixed-dose combination of tiotropium and the novel once-daily LABA olodaterol will also be available in Japan. Olodaterol is a highly selective and nearly full $\beta_{2}$-agonist that provides 24 -hour bronchodilation in patients with COPD. ${ }^{19}$ Once-daily dosing seems to be more convenient and may enhance compliance, leading to improved overall clinical outcomes in patients with COPD. ${ }^{20}$

\section{Epidemiology and treatment of COPD in Japan}

More than 95\% of COPD patients in Japan have the smokingrelated form of the disease because oil and gas, rather than biomass fuels, are used throughout the country. The Nippon COPD Epidemiology (NICE) study ( $\mathrm{N}=2,343)$ demonstrated that the prevalence of COPD in Japan is comparable to that in other developed countries. ${ }^{21}$ The study was the first 
spirometry-based study on the prevalence of airflow limitation in Japan and revealed that more than 5.3 million people $-8.5 \%$ of the population aged 40 years and older - should be diagnosed as having COPD based on the Global Initiative for Chronic Obstructive Lung Disease (GOLD) criteria $\left(\mathrm{FEV}_{1} /\right.$ FVC [forced vital capacity] $<70 \%$ ). That prevalence is dramatically higher than previous COPD prevalence estimates from the Ministry of Health and Welfare, suggesting a very high degree of under recognition of COPD in Japan.

Another study in Japan ( $\mathrm{N}=1,040)$ also indicated significant under diagnosis of COPD, reporting that $27 \%$ of COPD patients were found among patients treated for diseases other than chronic respiratory disease in primary care settings. ${ }^{22}$ About $61 \%$ of the patients had moderate-to-severe COPD according to the international guidelines $\left(\mathrm{FEV}_{1}<80 \%\right.$ predicted $)$. However, $31.3 \%$ did not receive any clinical intervention (smoking cessation advice and/or drug administration). Another study determined the proportion of Japanese patients with smoking histories being treated for cardiovascular disease who had concurrent airflow limitation compatible with COPD. ${ }^{23}$ The study $(\mathrm{N}=995)$ indicated that a quarter of outpatients with cardiovascular disease had COPD, but in almost all of them, the condition was undiagnosed. The prevalence of airflow limitation compatible with COPD was $27.0 \%$, and $87.7 \%$ of those patients did not have a prior diagnosis of COPD.

A global survey of patients with physician-diagnosed COPD or emphysema or with physician-diagnosed or symptom-based chronic bronchitis reported a prevalence of COPD of $7 \%$ in a Japanese population aged 40 years or older. ${ }^{24}$ The phenotypic distribution involving both airway and systemic inflammation, in addition to airway obstruction, is similar to that previously described in Western studies. ${ }^{25}$ A global survey ${ }^{24}$ also confirmed findings that COPD causes a high societal and personal burden, as demonstrated by high levels of symptoms, poor health status, and high frequency of severe exacerbations of COPD. Given the high prevalence of smoking in Japan, coupled with its aging population, the prevalence of the disease in the country is likely to increase over the next 20-40 years, further increasing the burden of COPD.

The Japanese Respiratory Societies acknowledge the recent dissemination of $\mathrm{GOLD}^{26}$ as a major worldwide contribution to the fight against COPD. Putting emphasis on smoking exposure as a primary etiology of the disease, the Japanese guidelines describe COPD as:

A common preventable and treatable disease, characterized by persistent airflow obstruction that is usually progressive and associated with an enhanced chronic airway inflammation in response to noxious particles or gases, primarily tobacco smoking exposure. ${ }^{27}$

Once COPD is diagnosed and its severity established, nonpharmacologic and pharmacologic treatments aim to reduce the symptoms and exacerbations (Figure 1). Shortacting $\beta_{2}$-agonists (SABAs) or short-acting muscarinic receptor antagonists (SAMAs) are used on an as-needed basis for symptomatic relief in the early stages. The current Japanese guidelines recommend consideration of a monotherapy using a long-acting bronchodilator (LAMA or LABA) in moderate COPD to optimize the symptom benefit for patients. ${ }^{27} \mathrm{~A}$ combination of a LAMA and a LABA is prescribed if symptoms persist even after individual bronchodilator monotherapy. Although the optimal sequencing of monotherapies and combination bronchodilators where LAMA/LABA combination therapy may be positioned in the treatment algorithm for COPD is still uncertain, published evidence to date supports the use of a combination therapy with a LAMA and a LABA in COPD patients with advanced stages. ${ }^{9-11,18}$

ICSs in combination with long-acting bronchodilators are indicated in COPD patients at risk of exacerbation and/or in those with the asthma-COPD overlap syndrome (ACOS), but never as a stand-alone therapy. ${ }^{28}$ Although identification of the clinical factors that predict corticosteroid responsiveness in COPD patients has not been established in large clinical trials, the overlap phenotype with asthma has a good therapeutic response to ICSs in addition to bronchodilators. ${ }^{29}$ The Japanese guidelines currently recommend that ICS/LABA be given to symptomatic and exacerbation-prone patients, although the COPD market in Japan is dominated by the LAMA tiotropium and the ICS/LABA salmeterol/fluticasone propionate combination (SFC), regardless of the presence or absence of comorbid asthma.

Low frequency of COPD exacerbations is noted in Japan; a Hokkaido COPD cohort study of 279 patients found a very low-exacerbation frequency during the 5 -year follow-up. ${ }^{30}$ Exacerbation frequency (events per person per year) was 0.06 for hospital admission definitions. In this study, 73\% of the participants were taking some daily medications, 52\% were taking anticholinergics, 35\% $\beta_{2}$-agonists, $44 \%$ theophylline, and $14 \%$ ICS. Low frequency of exacerbations is among the major factors that may affect the therapeutic option in Japan. Another study also showed that 38.7\%, 35.1\%, 32.0\%, and $37.6 \%$ of COPD patients in Asian countries were taking theophylline, an inhaler containing a combination of a corticosteroid and a LABA, an inhaled SABA, and an inhaled LAMA, respectively. ${ }^{31}$ The usage of each medication appeared to differ from those used in Western countries. Theophylline, 


\section{Japanese Respiratory Society COPD guidelines (4th edition)}

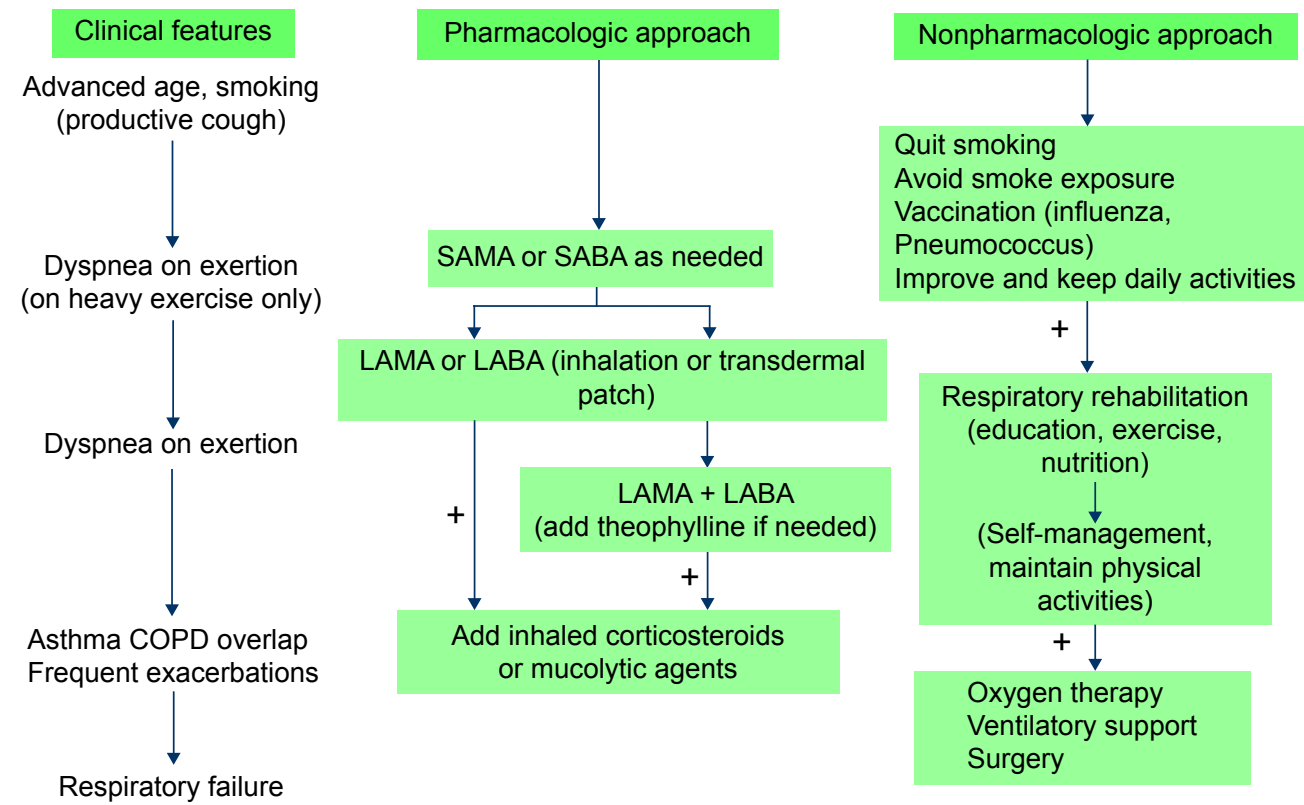

Figure I Algorithm of management of stable COPD in Japan.

Notes: The treatment strategy should be selected on the basis of a comprehensive evaluation of severity, taking into account the degree of manifestations in addition to the degree of airflow obstruction. In cases of repeated exacerbations, introduction of ICSs in addition to long-acting bronchodilators should be considered. Translated and modified from The Japanese Respiratory Society by Hizawa N. Guidelines for the Diagnosis and Treatment of COPD. 4th ed. Tokyo, Japan: Japanese Respiratory Society; 20I3. ${ }^{27}$

Abbreviations: COPD, chronic obstructive pulmonary disease; ICSs, inhaled corticosteroids; LABA, long-acting $\beta_{2}$-agonist; LAMA, long-acting muscarinic antagonist; SABA, Short-acting $\beta_{2}$-agonist; SAMA, short-acting muscarinic receptor antagonist.

especially, was the most prevalent and appears to be used more when compared to Western countries. ${ }^{32}$ In addition, transdermal tulobuterol is frequently used for COPD treatment in Japan. This formulation of tulobuterol was designed to maintain drug levels at constant effective concentrations over a 24-hour period when applied once daily. The efficacy of this drug in COPD patients was investigated in a randomized comparative study using inhaled salmeterol, which is used for the treatment of COPD. ${ }^{33}$

There is no question that $\mathrm{FEV}_{1}$ is a key factor in the diagnosis, characterization of severity, prognosis, and follow-up of patients with COPD. However, it is now recognized that the treatment of COPD should involve more than improving lung function since the impact of lung-function impairment varies greatly from patient to patient. Exacerbations and symptoms also have a significant impact on the health status of these patients. ${ }^{34,35}$ As a result, the GOLD strategy document, updated in 2011 and 2013, has proposed a new, multidimensional approach to assess patients with COPD. The revised classification system emphasizes the heterogeneity among patients with COPD. It recommends that COPD management and treatment should consider both the disease impact, determined by assessment of the symptoms and activity limitation, and the future risk of exacerbations, determined by assessment of airflow limitation or the exacerbation history. This combined assessment of COPD results in the grouping of patients into one of four categories: (A) low risk, fewer symptoms; (B) low risk, more symptoms; (C) high risk, fewer symptoms; and (D) high risk, more symptoms. ${ }^{36}$ However, given that this strategy has not been tested in a clinical trial, and given that many controversies and unanswered questions regarding this approach remain, ${ }^{37,38}$ the Japanese guidelines do not currently apply it.

\section{Choosing between LAMA/LABA and ICS/LABA in the treatment of COPD}

The ILLUMINATE study ${ }^{39}$ has provided interesting information on the relative effects on lung function of a LAMA/ LABA versus an ICS/LABA combination; it showed significant, sustained, and clinically meaningful improvements in airflow obstruction with indacaterol plus glycopyrronium versus the ICS/LABA salmeterol/fluticasone. The LAMA/ LABA combination was also more effective at preventing exacerbations, specifically in less exacerbation-prone COPD patients. A real-life, prospective study suggested that the withdrawal of ICSs in patients at low risk of exacerbation, namely patients with moderate airflow limitation 
$\left(\mathrm{FEV}_{1}>50 \%\right.$ predicted) and less than two exacerbations in the year preceding the study, can be safe, provided that the patients are left on maintenance treatment with long-acting bronchodilators. ${ }^{40}$ In the recent Indacaterol: Switching Nonexacerbating Patients with Moderate COPD from Salmeterol/Fluticasone to Indacaterol (INSTEAD) trial involving patients with moderate COPD who had no exacerbations during the previous year, switching patients from an ICS/ LABA combination to an ultra-LABA did not increase the exacerbation rate over 26 weeks of treatment. ${ }^{41}$ Together, these studies support the notion that, at least in a subgroup of patients with moderate-to-severe COPD, combining two bronchodilators of different classes is an appropriate choice, rather than adding an ICS, if maintenance treatment with a single long-acting bronchodilator does not suffice.

On the other hand, the evidence clearly shows that ICS/ LABA combinations significantly reduce the yearly rate of moderate and severe exacerbations and improve lung function, when compared with LABAs alone, ${ }^{2}$ particularly in patients with histories of frequent exacerbations. ${ }^{42}$ In addition, the WISDOM study has shown that withdrawing ICSs in patients with COPD treated with two bronchodilators is associated with a significant worsening of $\mathrm{FEV}_{1} \cdot{ }^{18}$ In terms of mortality, although the TORCH (TOwards a Revolution in COPD Health) study failed to show a significant beneficial effect of an ICS/LABA combination on all-cause mortality rates, ${ }^{2}$ the statistical difference was borderline, and a recent database analysis showed that in a real-life scenario, an ICS/LABA combination significantly reduced mortality when compared with a bronchodilator alone. ${ }^{43}$ Participants in these studies included COPD patients with an asthma component, who also reap the benefit from ICS treatments.

Although ICSs reduce the rates of moderate or severe exacerbations of COPD, ICSs have been linked with an increased risk of pneumonia in individuals with COPD. ${ }^{44,45}$ Factors indicated to be associated with this increased risk among patients with COPD treated with fluticasone furoate/ vilanterol included older age, lower body mass index, current smoking, previous occurrence of pneumonia, and poorer lung function. ${ }^{42}$ A cluster analysis using a data-driven recursive partitioning algorithm was applied to baseline data from two pooled 1-year randomized exacerbation trials $(\mathrm{N}=3,255)$ of fluticasone furoate/vilanterol or vilanterol alone to identify distinct patient groups at greatest risk of pneumonia. ${ }^{46}$ This cluster analysis also showed that patients at greater risk of pneumonia had severe obstruction and either a lower body mass index or a pneumonia history and greater comorbidities.
Considering this, it is an unwise approach to add ICSs just because patients have severe airflow obstruction and frequent exacerbations; instead, it is critically important to understand the need to identify a subgroup of patients with COPD who respond better to $\mathrm{ICSs}^{47}$

Inflammation, predominantly neutrophilic, contributes to the narrowing of the small airways in patients with $\mathrm{COPD}^{48}$ and is increased during acute exacerbations. ${ }^{49}$ However, in $10 \%-30 \%$ of patients with COPD, evidence has been reported of eosinophilic airway inflammation both during stable periods and during acute exacerbations. ${ }^{49-51}$ Exacerbations in individuals with COPD but no history of asthma can also present along with airway eosinophilia. ${ }^{52}$ These patients have good short- and long-term responses to glucocorticoids, and a raised blood eosinophil count has been shown to be a good biomarker of this pattern of airway inflammation. ${ }^{53-55}$ Titration of ICS treatment to reduce the concentration of airway eosinophils attenuates the frequency of severe acute exacerbations of COPD. ${ }^{51}$ An increased peripheral blood eosinophil count is also associated with an increased risk of death from $\mathrm{COPD}^{56}$ and with a better response to oral prednisolone in patients with a moderate ${ }^{57}$ or severe ${ }^{58}$ exacerbation.

The Investigating New Standards for Prophylaxis in Reducing Exacerbations (INSPIRE) study compared the effect of the anti-inflammatory/bronchodilator combination of SFC with the bronchodilator tiotropium bromide on the rate of moderate and/or severe exacerbations over a 2-year treatment period. ${ }^{59}$ The study observed more episodes of reported pneumonia in the SFC-treated patients. Although the overall exacerbation rate did not differ between treatments, the nature of the exacerbations did differ; there were fewer episodes requiring oral corticosteroid treatment in the SFC group than in the tiotropium group, but relatively more patients were treated with antibiotics in the SFC group. This finding provides indirect evidence that these treatments affect apparently similar patients in different ways, thus affecting the clinical judgment. The heterogeneity of the biologic response of COPD exacerbations has been investigated and four distinct biologic exacerbation clusters were identified: bacterial-, viral-, or eosinophilic-predominant, and pauciinflammatory. ${ }^{49}$ Bacteria- and sputum eosinophil-associated exacerbations rarely coexisted and were reliably predicted from the stable state, suggesting fundamental differences in the immunopathogenesis of the exacerbations. Therefore, these data are consistent with the view that bacterial and eosinophilic exacerbations may reflect instability within a complex and inherently unstable system, whereas viral exacerbations are more likely to represent acquisition of a 
new pathogen. Although the current guidelines recommend the use of systemic corticosteroids for COPD exacerbations, the magnitude of the benefit is marginal and their use is associated with significant side effects, ${ }^{60}$ and targeting corticosteroid therapy in a subgroup of exacerbations dependent on the peripheral eosinophil count may reduce inappropriate use of systemic corticosteroids.

Because ICSs are anti-inflammatory drugs and not bronchodilators, the presence of sputum and/or blood eosinophilia is a good indicator to use ICSs in the treatment of COPD. In patients with asthma, blood eosinophils had the highest accuracy in predicting eosinophilic airway inflammation. ${ }^{61}$ Therefore, the use of blood eosinophils can facilitate individualized treatment and management of COPD patients by identifying the eosinophilic nature of the airway inflammation. ${ }^{51,54,55}$

\section{Pharmacogenetics of LABA and LAMA in COPD patients}

The gene encoding the $\beta_{2}$-adrenergic receptor $(A D R B 2)$ is among the gene targets studied most extensively in asthma and COPD, and variations in $A D R B 2$ have been suggested to play a role in the differential response to $\beta$-agonist therapy in asthma and COPD. ${ }^{62}$ In fact, the $\beta_{2}$-adrenergic receptor is involved in a number of pathophysiological processes throughout the body. Several studies have demonstrated its participation in the aging process of the respiratory system, heart, vessels, skeletal muscle, immune system, pancreatic islets, and bone, ${ }^{63,64}$ and this participation is significantly involved in the pathobiology of COPD.

The effect of different $A D R B 2$ polymorphisms (16 and 27 amino acid positions) on COPD exacerbations is described in patients treated with salmeterol or tiotropium, either alone or concomitantly with an ICS at baseline. The results of this subanalysis of the Prevention Of Exacerbations with Tiotropium-COPD (POET-COPD) trial showed that Arg16 homozygous patients had better exacerbation outcomes in response to salmeterol than did patients carrying the Gly16 allele, ${ }^{65}$ suggesting a potential differential Arg16Gly genotype effect on treatment response to LABAs. ${ }^{66}$

In vitro experiments in human airway smooth muscle cells have suggested that, in response to long-term agonist exposure, $A D R B 2$ Arg16 alleles exhibited greater resistance to receptor downregulation than $\operatorname{did} A D R B 2$ Gly16 alleles. ${ }^{67}$ The Arg16 $\beta_{2}$-adrenoceptor might therefore be expressed at greater levels than the Gly16 $\beta_{2}$-adrenoceptor within the airways. Accordingly, one could speculate that perhaps in Arg16 homozygous patients with COPD, this resistance allows salmeterol to provide increased bronchodilation so that its effects are equivalent to tiotropium in that group; in contrast, individuals carrying the Gly16 allele might be more sensitive to stimuli resulting in bronchoconstriction and, therefore, have more exacerbations than individuals carrying the Arg16 allele. Alternatively, since altering $\beta_{2}$-adrenergic receptor expression might affect the function of the cholinergic receptors controlling airway contractility, ${ }^{6}$ the possibility remains that cholinergic receptors explain the significant association observed between the Gly16 allele and the increased frequency of COPD exacerbations.

The US Food and Drug Administration has issued recommendations on how $\mathrm{LABAs}$ should be used to treat asthma. ${ }^{68}$ Several studies have shown dissociation between the bronchodilator (effects on $\mathrm{FEV}_{1}$ ) and bronchoprotective (effects on exacerbations) effects of LABA, ${ }^{69}$ which may underlie the significant deterioration in asthma control caused by long-term usage of LABA. The data reported by McGraw et $\mathrm{al}^{70}$ suggested that persistent high-level activation of the $\beta_{2}$-adrenergic receptor leads to increased expression of phospholipase C- $\beta$ (PLC $\beta$ ) in airway smooth muscle. Since agonists such as acetylcholine, histamine, and leukotrienes that cause airway smooth muscle contraction do so by acting on receptors that couple to Gq and activate PLC $\beta$, chronic $\beta$-agonists might augment the effects of these bronchoconstrictors. Accordingly, the presence of the Arg16 allele, which demonstrates resistance to downregulation and therefore has persistent high-level activation of the $\beta_{2}$-adrenergic receptor, might negatively affect the clinical efficacy of regular use of LABAs in patients with asthma. In the LARGE trial, ${ }^{71}$ half of the Arg16 homozygous patients with asthma experienced worsening of methacholine responsiveness despite their airway functions having been improved by addition of a LABA to an ICS. Collectively, in patients with COPD, especially in terms of exacerbations, compared with LAMAs, LABAs may be detrimental in Gly16 homozygous patients without asthma, while LABAs may be detrimental in Arg16 homozygous patients with asthma (ACOS), indicating that unless contraindicated, LAMAs rather than LABAs should be the choice as the first-line bronchodilator. Future studies will examine whether the effects of LAMA/LABA combinations are dependent on the $A D R B 2$ Arg16Gly genotype.

\section{Approach to COPD based on the disease phenotype}

Although the mainstays of COPD management, including inhaled LAMAs or LABAs alone or combined with ICSs, have been shown in randomized clinical trials to improve lung function and quality of life and to reduce exacerbation 
frequency, ${ }^{1,2,42}$ the rising number of both single-agent and combination therapies for COPD increases the number of treatment options and, hence, makes the treatment choice more complex.

COPD is a heterogeneous multifactorial disorder associated with an abnormal inflammatory response of the peripheral airways and with variable morphologic, physiologic, and clinical phenotypes. ${ }^{72}$ Definition of these phenotypes will likely allow us to understand which patients may benefit from the addition of an ICS and which patient should be treated with a longacting bronchodilator alone. For example, the emphysema phenotype presents a poor therapeutic response to existing anti-inflammatory drugs, and LABAs and/or LAMAs together with rehabilitation are the primary treatments of choice. ICSs fail to suppress inflammation owing to a marked reduction in histone deacetylase-2, the nuclear enzyme that corticosteroids require to switch off activated inflammatory genes. ${ }^{73}$

The ACOS has garnered much interest. ${ }^{74}$ Gershon et $\mathrm{al}^{43}$ reported the results of an investigation of the comparative efficacy of using a LABA alone or together with an ICS in elderly patients with COPD: the relative risk of death or hospitalization was approximately $8 \%$ less than among those treated with LABAs alone. The benefit associated with ICS/ LABA use was greatest among patients with a prior diagnosis of asthma, suggesting that ACOS is a common clinical problem among older COPD patients and merits treatment with an ICS/LABA combination for this subphenotype. The presence of blood eosinophilia in COPD patients without asthma can also identify those more responsive to corticosteroids. ${ }^{51,55}$ In addition, one study demonstrated that the presence of an allergic phenotype is associated with increased risk of lower respiratory symptoms and respiratory exacerbations among individuals with COPD,${ }^{75}$ suggesting that the presence of allergic sensitization is another good indicator for ICS/ LABA treatment because allergic sensitization, assessed by allergen-specific IgE or skin-prick testing, is a known risk factor for asthma and its severe symptoms.

The exacerbator phenotype is characterized by at least two exacerbations in the previous year. ${ }^{76}$ Although exacerbations become more frequent and severe as COPD progresses, the rate at which they occur appears to reflect an independent susceptibility phenotype. ${ }^{76}$ Among the patients who had moderate COPD, 22\% had frequent exacerbations; exacerbations were more common among patients with airway hyperreactivity, such as wheezing or a history of asthma. This finding may explain, at least partly, why ICS/LABA combinations were more effective than LAMA/LABA combinations at preventing exacerbations in exacerbation-prone COPD patients.
ICS/LABA is expected to have more impact on exacerbations in patients with asthma components to their COPD.

Figure 2 shows a proposal for positioning ICSs and bronchodilators in COPD in clinical practice. This scheme uses two dimensions: the presence of airway eosinophilia and airflow obstruction. Among older individuals with COPD, use of LABAs and LAMAs may be associated with increased risks of cardiovascular events, requiring closer monitoring. ${ }^{77}$ In addition, adding a LABA to a LAMA in patients with lowcomplexity COPD appeared just to increase costs without providing significant benefits. Therefore, if $\mathrm{FEV}_{1}$ is $50 \%$ or greater than the predicted $\mathrm{FEV}_{1}$, monotherapy using either a LABA or a LAMA should remain the management of stable COPD. Although LABAs and LAMAs provided clinically relevant improvements in lung function with comparable safety profiles, LAMAs always afforded greater protection from exacerbations. ${ }^{65,78}$ Furthermore, considering the genetic influences of the Arg16Gly at the $A D R B 2$ gene on the therapeutic outcomes of LABA in patients with COPD, LAMA monotherapy early in the course of COPD among patients with low-to-moderate disease complexity will be the first treatment choice rather than LABA monotherapy. If the presence of eosinophilic inflammation in the airways

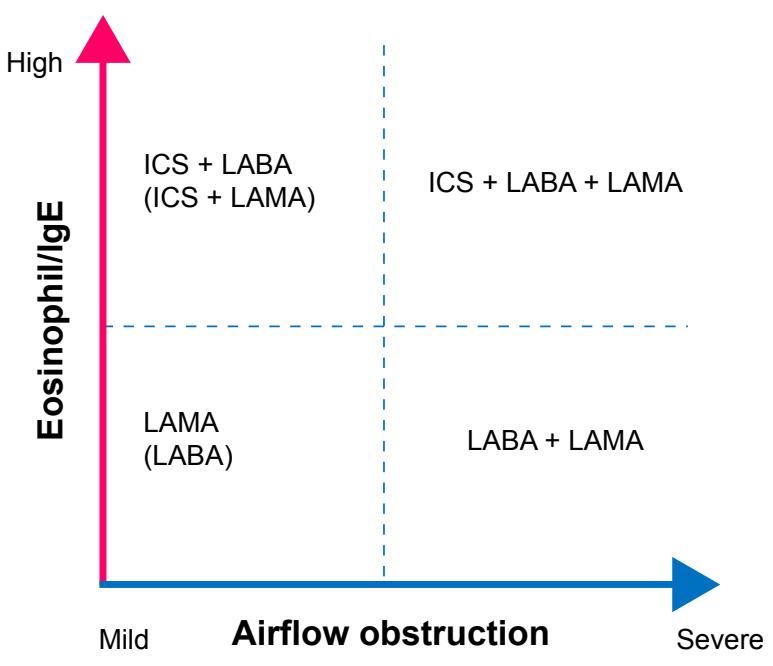

Figure 2 Approach to COPD on the basis of the degree of airflow obstruction and peripheral blood eosinophil counts.

Notes: LAMA monotherapy, early in the course of COPD, among patients with FEV of $50 \%$ or greater of the predicted $\mathrm{FEV}$, will be the first choice rather than LABA monotherapy. If the presence of eosinophilic inflammation in the airways is indicated on the basis of sputum or blood eosinophilia, the initial choice could be an ICS/LABA combination. For patients with frequent exacerbations, whether ICS/LABA should be regularly administered depends on the presence of eosinophilic exacerbation as described in the text. The escalation of bronchodilators and ICSs is recommended in patients with stable COPD who remain breathless or have exacerbations. Ultimately, patients with severe symptoms and/or frequent exacerbations may require "triple therapy" with a LAMA, a LABA, and an ICS.

Abbreviations: COPD, chronic obstructive pulmonary disease; $F E V_{1}$, forced expiratory volume in I second; ICSs, inhaled corticosteroids; LABA, long-acting $\beta_{2}$ agonist; LAMA, long-acting muscarinic antagonist. 
is indicated on the basis of sputum or blood eosinophilia, the initial choice could be an ICS/LABA combination. Given that noneosinophilic asthma is rather resistant to ICS therapy ${ }^{79}$ and that the perceived overlap between asthma and COPD is exaggerated owing to the common misconception that a significant bronchodilator response in patients with COPD implies the coexistence of an asthma component, I would emphasize the importance of ICS use based on the presence of eosinophilic inflammation rather than that based just on a previous diagnosis of asthma. Figure 2 proposes the escalation of bronchodilators and ICSs in COPD if exacerbations or breathlessness persist. Ultimately, patients with severe symptoms and/or frequent exacerbations may require "triple therapy" with a LAMA, a LABA, and an ICS. The components of triple therapy have different molecular mechanisms of action, so there is a good rationale for the combined use of these drugs to maximize the clinical benefits. It has been demonstrated that in some patients, triple therapy, in which an anticholinergic is added to an ICS and LABA, was associated with greater improvements in lung function and quality of life and with reduced rates of hospitalization when compared with anticholinergic therapy alone. ${ }^{80-82}$

I acknowledge that my proposal requires validation but, given that the importance of eosinophilic inflammation in the treatment of COPD is currently rather ignored in clinical practice, I think that emphasizing the therapeutic approach taking eosinophilic inflammation into account has the possibility of greatly improving the well-being of individuals with COPD. I also acknowledge that several questions related to the exact role of eosinophilic inflammation in COPD remain unanswered. ${ }^{83}$ For example, whether, in COPD patients with airway eosinophilia, ICSs will modify disease progression by controlling eosinophilic inflammation and possibly alter mortality is unknown, but warrants further investigation.

\section{Conclusion}

Bronchodilators are central to the management of COPD, and current guidelines recommend the addition of a second bronchodilator to initial monotherapy in moderate COPD to maximize bronchodilation. The greater impacts of LAMA/ LABA combinations on $\mathrm{FEV}_{1}$, patient-centered outcomes such as dyspnea, rescue-medication-use, and quality of life have been established in comparison to the impacts of individual drugs used alone. The accumulating evidence clearly indicates that we should approach each patient with COPD on the basis of the respective phenotype of that patient. This will involve identifying eosinophilic inflammation and also taking into account factors such as the presence of emphysema, chronic bronchitis, or frequent exacerbations. Furthermore, blood eosinophil levels have a remarkable intrapatient daily variation and relatively poor data are currently available in literature on the possible roles of eosinophilic inflammation in the pathobiology of COPD. Therefore, at present, the eosinophil count should be considered carefully and may be restricted to those with severe airflow obstruction with symptoms secondary to recurrent COPD exacerbations. Further studies should be designed to provide substantial evidence for future guideline recommendations. Here, I have put some emphasis on the importance of evaluating eosinophilic airway inflammation to ensure appropriate use of ICSs. In addition, LAMA/LABA combinations should not be prescribed without confirming the presence of severe airflow obstruction because these agents are strong bronchodilators after all.

\section{Disclosure}

$\mathrm{NH}$ has received grants and support for research in respiratory disease from the following organizations in the last 5 years: Astellace, AstraZeneca, Boehringer Ingelheim, GlaxoSmithKline, Kyorin, MSD, Novartis, and Chugai Pharmaceutical. He has received payments for lectures/speaking from Astellace, AstraZeneca, Boehringer Ingelheim, GlaxoSmithKline, Kyorin, MSD, Novartis. The author reports no other conflicts of interest in this work.

\section{References}

1. Tashkin DP, Celli B, Senn S, et al. A 4-year trial of tiotropium in chronic obstructive pulmonary disease. $N$ Engl J Med. 2008;359:1543-1554.

2. Calverley PM, Anderson JA, Celli B, et al. Salmeterol and fluticasone propionate and survival in chronic obstructive pulmonary disease. N Engl J Med. 2007;356:775-789.

3. Bateman ED, Ferguson GT, Barnes N, et al. Dual bronchodilation with QVA149 versus single bronchodilator therapy: the SHINE study. Eur Respir J. 2013;42(6):1484-1494.

4. O'Donnell DE, Sciurba F, Celli B, et al. Effect of fluticasone propionate/ salmeterol on lung hyperinflation and exercise endurance in COPD. Chest. 2006;130:647-656.

5. O'Donnell DE, Flüge T, Gerken F, et al. Effects of tiotropium on lung hyperinflation, dyspnoea and exercise tolerance in COPD. Eur RespirJ. 2004;23:832-840.

6. Cazzola M, Molimard M. The scientific rationale for combining long-acting $\beta 2$-agonists and muscarinic antagonists in COPD. Pulm Pharmacol Ther. 2010;23:257-267.

7. Ikeda T, Anisuzzaman AS, Yoshiki H, et al. Regional quantification of muscarinic acetylcholine receptors and $\beta$-adrenoceptors in human airways. Br J Pharmacol. 2012;166(6):1804-1814.

8. Cazzola M, Calzetta L, Page CP, et al. Pharmacological characterization of the interaction between aclidinium bromide and formoterol fumarate on human isolated bronchi. Eur J Pharmacol. 2014;745:135-143.

9. Tashkin DP, Donohue JF, Mahler DA, et al. Effects of arformoterol twice daily, tiotropium once daily, and their combination in patients with COPD. Respir Med. 2009;103:516-524.

10. van Noord JA, Aumann JL, Janssens E, et al. Comparison of tiotropium once daily, formoterol twice daily and both combined once daily in patients with COPD. Eur Respir J. 2005;6:214-222. 
11. Mahler DA, D’Urzo A, Bateman ED, et al. Concurrent use of indacaterol plus tiotropium in patients with COPD provides superior bronchodilation compared with tiotropium alone: a randomised, double-blind comparison. Thorax. 2012;67:781-788.

12. Aaron SD, Vandemheen KL, Fergusson D, et al. Tiotropium in combination with placebo, salmeterol, or fluticasone-salmeterol for treatment of chronic obstructive pulmonary disease: a randomized trial. Ann Intern Med. 2007;146(8):545-555.

13. Dahl R, Chapman KR, Rudolf M, et al. Safety and efficacy of dual bronchodilation with QVA149 in COPD patients: the ENLIGHTEN study. Respir Med. 2013;107(10):1558-1567.

14. Santus, et al. Assessment of acute bronchodilator effects from specific airway resistance changes in stable COPD patients. Respir Physiol Neurobiol. 2014;197:36-45.

15. Martin J, Carrizo S, Gascon M, et al. Inspiratory capacity, dynamic hyperinflation, breathlessness, and exercise performance during the 6-minute-walk test in chronic obstructive pulmonary disease. Am J Respir Crit Care Med. 2001;163:1395-1399.

16. Matarese A, Santulli G. Angiogenesis in chronic obstructive pulmonary disease: a translational appraisal. Transl Med Uni Sa. 2012;3:49-56.

17. Wedzicha J, Decramer M, Seemungal T. The role of bronchodilator treatment in the prevention of exacerbations of COPD. Eur Respir J. 2012;40:1545-1554

18. Magnussen H, Disse B, Rodriguez-Roisin R, et al. Withdrawal of inhaled glucocorticoids and exacerbations of COPD. N Engl J Med. 2014;371: 1285-1294.

19. Buhl R, Maltais F, Abrahams R, et al. Tiotropium and olodaterol fixeddose combination versus mono-components in COPD (GOLD 2-4). Eur Respir J. 2015;45(4):969-979.

20. Claxton AJ, Cramer J, Pierce C. A systematic review of the associations between dose regimens and medication compliance. Clin Ther. 2001;23(8):1296-1310.

21. Fukuchi Y, Nishimura M, Ichinose M, et al. COPD in Japan: the Nippon COPD Epidemiology study. Respirology. 2004;9:458-465.

22. Takahashi $\mathrm{T}$, Ichinose $\mathrm{M}$, Inoue $\mathrm{H}$, et al. Underdiagnosis and undertreatment of COPD in primary care settings. Respirology. 2003;8: 504-508.

23. Onishi K, Yoshimoto D, Hagan GW, et al. Prevalence of airflow limitation in outpatients with cardiovascular diseases in Japan. Int J Chron Obstruct Pulmon Dis. 2014;9:563-568.

24. Landis SH, Muellerova H, Mannino DM, et al. Continuing to confront COPD international patient survey: methods, COPD prevalence, and disease burden in 2012-2013. Int J Chron Obstruct Pulmon Dis. 2014 9:597-611

25. Ishikawa N, Hattori N, Kohno N, et al. Airway inflammation in Japanese COPD patients compared with smoking and nonsmoking controls. Int J Chron Obstruct Pulmon Dis. 2015;10(1):185-192.

26. Pauwels RA, Buist AS, Calverley PM, et al. Global strategy for the diagnosis, management, and prevention of chronic obstructive pulmonary disease. GOLD executive summary. Am J Respir Crit Care Med. 2001;163:1256-1276.

27. The Japanese Respiratory Society. Guidelines for the Diagnosis and Treatment of COPD. 4th ed. Tokyo, Japan: Japanese Respiratory Society; 2013.

28. Vestbo J, Hurd SS, Agusti AG, et al. Global strategy for the diagnosis, management and prevention of chronic obstructive pulmonary disease, GOLD executive summary. Am J Respir Crit Care Med. 2013;187: 347-365.

29. Pizzichini E, Pizzichini MM, Gibson P, et al. Sputum eosinophilia predicts benefit from prednisone in smokers with chronic obstructive bronchitis. Am J Respir Crit Care Med. 1998;158(5):1511-1517.

30. Suzuki M, Makita H, Ito YM, et al. Clinical features and determinants of COPD exacerbation in the Hokkaido COPD cohort study. Eur Respir J. 2014;43(5):1289-1297.

31. Oh YM, Bhome AB, Boonsawat W, et al. Characteristics of stable chronic obstructive pulmonary disease patients in the pulmonology clinics of seven Asian cities. Int J Chron Obstruct Pulmon Dis. 2013;8:31-39.
32. Seaman J, Leonard AC, Panos RJ. Health care utilization history, GOLD guidelines, and respiratory medication prescriptions in patients with COPD. Int J Chron Obstruct Pulmon Dis. 2010;5:89-97.

33. Fukuchi Y, Nagai A, Seyama K, et al; Research Group TB. Clinical efficacy and safety of transdermal tulobuterol in the treatment of stable COPD: an open-label comparison with inhaled salmeterol. Treat Respir Med. 2005;4:447-455.

34. Sin DD, McAlister FA, Man SF, Anthonisen NR. Contemporary management of chronic obstructive pulmonary disease: scientific review. JAMA. 2003;290(17):2301-2312.

35. Bahadori K, FitzGerald JM. Risk factors of hospitalization and readmission of patients with COPD exacerbation: a systematic review. Int J Chron Obstruct Pulmon Dis. 2007;2:241-251.

36. Global initiative for chronic Obstructive Lung Disease (GOLD). 2013. Available from: http:/www.goldcopd.org/Guidelines/guideline-2013gold-report.html. Accessed May 14, 2015.

37. Yusen RD. Evolution of the GOLD documents for the diagnosis, management, and prevention of chronic obstructive pulmonary disease. Controversies and questions. Am J Respir Crit Care Med. 2013; 188(1):4-5.

38. Price DB, Baker CL, Zou KH, et al. Real-world characterization and differentiation of the global initiative for chronic obstructive lung disease strategy classification. Int J Chron Obstruct Pulmon Dis. 2014;9: 551-561.

39. Vogelmeier CF, Bateman ED, Pallante J, et al. Efficacy and safety of once-daily QVA149 compared with twice-daily salmeterol-fluticasone in patients with chronic obstructive pulmonary disease (ILLUMINATE): a randomised, double-blind, parallel group study. Lancet Respir Med. 2013;1:51-60.

40. Rossi A, Guerriero M, Corrado A, et al. Withdrawal of inhaled corticosteroids can be safe in COPD patients at low risk of exacerbation: a real-life study on the appropriateness of treatment in moderate COPD patients (OPTIMO). Respir Res. 2014;15:77.

41. Rossi A, van der Molen T, Olmo RD, et al. INSTEAD: a randomized switch trial of indacaterol versus salmeterol/fluticasone in moderate COPD. Eur Respir J. 2014;44:1548-1556.

42. Dransfield MT, Bourbeau J, Jones PW, et al. Once-daily inhaled fluticasone furoate and vilanterol versus vilanterol only for prevention of exacerbations of COPD: two replicate double-blind, parallelgroup, randomised controlled trials. Lancet Respir Med. 2013;1(3): 210-223.

43. Gershon AS, Campitelli MA, Croxford R, et al. Combination longacting $\beta$-agonists and inhaled corticosteroids compared with long-acting $\beta$-agonists alone in older adults with chronic obstructive pulmonary disease. JAMA. 2014;312:1114-1121.

44. Finney L, Berry M, Singanayagam A, et al. Inhaled corticosteroids and pneumonia in chronic obstructive pulmonary disease. Lancet Respir Med. 2014;2:919-932.

45. Suissa S, Patenaude V, Lapi F, Ernst P. Inhaled corticosteroids in COPD and the risk of serious pneumonia. Thorax. 2013;68: 1029-1036.

46. DiSantostefano RL, Li H, Hinds D, et al. Risk of pneumonia with inhaled corticosteroid/long-acting $\beta 2$ agonist therapy in chronic obstructive pulmonary disease: a cluster analysis. Int J Chron Obstruct Pulmon Dis. 2014:9:457-468.

47. Calverley PM. Treating COPD in the real world. JAMA. 2014;312: 1101-1102.

48. Hogg JC, Chu F, Utokaparch S, et al. The nature of small-airway obstruction in chronic obstructive pulmonary disease. NEngl J Med. 2004;350 2645-2653.

49. Bafadhel M, McKenna S, Terry S, et al. Acute exacerbations of chronic obstructive pulmonary disease: identification of biologic clusters and their biomarkers. Am J Respir Crit Care Med. 2011;184: 662-671.

50. Brightling CE, Monteiro W, Ward R, et al. Sputum eosinophilia and short-term response to prednisolone in chronic obstructive pulmonary disease: a randomised controlled trial. Lancet. 2000;356:1480-1485. 
51. Siva R, Green RH, Brightling CE, et al. Eosinophilic airway inflammation and exacerbations of COPD: a randomised controlled trial. Eur Respir J. 2007;29:906-913.

52. Saetta M, Di Stefano A, Maestrelli P, et al. Airway eosinophilia in chronic bronchitis during exacerbations. Am J Respir Crit Care Med. 1994;150: 1646-1652.

53. Brightling CE, McKenna S, Hargadon B, et al. Sputum eosinophilia and the short term response to inhaled mometasone in chronic obstructive pulmonary disease. Thorax. 2005;60:193-198.

54. Leigh R, Pizzichini MM, Morris MM, et al. Stable COPD: predicting benefit from high-dose inhaled corticosteroid treatment. Eur Respir J. 2006;27:964-971.

55. Kitaguchi Y, Komatsu Y, Fujimoto K, et al. Sputum eosinophilia can predict responsiveness to inhaled corticosteroid treatment in patients with overlap syndrome of COPD and asthma. Int J Chron Obstruct Pulmon Dis. 2012;7:283-289.

56. Hospers JJ, Schouten JP, Weiss ST, Rijcken B, Postma DS. Asthma attacks with eosinophilia predict mortality from chronic obstructive pulmonary disease in a general population sample. Am J Respir Crit Care Med. 1999;160:1869-1874.

57. Bafadhel M, McKenna S, Terry S, et al. Blood eosinophils to direct corticosteroid treatment of exacerbations of chronic obstructive pulmonary disease: a randomized placebo-controlled trial. Am J Respir Crit Care Med. 2012;186:48-55

58. Bafadhel M, Davies L, Calverley PM, et al. Blood eosinophil guided prednisolone therapy for exacerbations of COPD: a further analysis. Eur Respir J. 2014;44:789-791.

59. Wedzicha JA, Calverley PM, Seemungal TA, et al. The prevention of chronic obstructive pulmonary disease exacerbations by salmeterol/ fluticasone propionate or tiotropium bromide. Am J Respir Crit Care Med. 2008;177(1):19-26.

60. Niewoehner DE, Erbland ML, Deupree RH, et al. Effect of systemic glucocorticoids on exacerbations of chronic obstructive pulmonary disease. Department of Veterans Affairs Cooperative Study Group. N Engl J Med. 1999;340:1941-1947.

61. Wagener AH, de Nijs SB, Lutter R, et al. External validation of blood eosinophils, FENO and serum periostin as surrogates for sputum eosinophils in asthma. Thorax. 2015;70(2):115-120.

62. Hizawa N. Pharmacogenetics of chronic obstructive pulmonary disease. Pharmacogenomics. 2013;14(10):1215-1225.

63. Santulli G, Lombardi A, Sorriento D, et al. Age-related impairment in insulin release: the essential role of $\beta(2)$-adrenergic receptor. Diabetes. 2012;61(3):692-701.

64. Santulli G, Iaccarino G. Pinpointing beta adrenergic receptor in ageing pathophysiology: victim or executioner? Evidence from crime scenes. Immun Ageing. 2013;10(1):10.

65. Vogelmeier C, Hederer B, Glaab T, et al. Tiotropium versus salmeterol for the prevention of exacerbations of COPD. $N$ Engl J Med. 2011; 364:1093-1103.

66. Rabe KF, Fabbri LM, Israel E, et al. Effect of ADRB2 polymorphisms on the efficacy of salmeterol and tiotropium in preventing COPD exacerbations: a prespecified substudy of the POET-COPD trial. Lancet Respir Med. 2014;1:44-53.

67. Green SA, Turki J, Bejarano P, Hall IP, Liggett SB. Influence of $\beta 2$-adrenergic receptor genotypes on signal transduction in human airway smooth muscle cells. Am J Respir Cell Mol Biol. 1995;13:25-33.
68. Chowdhury BA, Dal Pan G. The FDA and safe use of long-acting $\beta$-agonists in the treatment of asthma. $N$ Engl J Med. 2010;362(13): 1169-1171.

69. Cheung D, Timmers MC, Zwinderman AH, et al. Long-term effects of a long-acting beta 2-adrenoceptor agonist, salmeterol, on airway hyperresponsiveness in patients with mild asthma. N Engl J Med. 1992; 327(17):1198-1203.

70. McGraw DW, Almoosa KF, Paul RJ, et al. Antithetic regulation by $\beta$-adrenergic receptors of $\mathrm{Gq}$ receptor signaling via phospholipase $\mathrm{C}$ underlies the airway $\beta$-agonist paradox. J Clin Invest. 2003;112: 619-626.

71. Wechsler ME, Kunselman SJ, Chinchilli VM, et al. Effect of $\beta 2$ adrenergic receptor polymorphism on response to long-acting $\beta 2$ agonist in asthma (LARGE trial): a genotype-stratified, randomised, placebocontrolled, crossover trial. Lancet. 2009;374(9703):1754-1764.

72. Pistolesi M, Camiciottoli G, Paoletti M, et al. Identification of a predominant COPD phenotype in clinical practice. Respir Med. 2008; $102: 367 \mathrm{e} 76$.

73. Barnes PJ. Glucocorticosteroids: current and future directions. Br J Pharmacol. 2011;163(1):29-43.

74. Gibson PG, Simpson JL. The overlap syndrome of asthma and COPD: what are its features and how important is it? Thorax. 2009;64(8): $728-735$.

75. Jamieson DB, Matsui EC, Belli A, et al. Effects of allergic phenotype on respiratory symptoms and exacerbations in patients with chronic obstructive pulmonary disease. Am J Respir Crit Care Med. 2013;188(2):187-192.

76. Hurst JR, Vestbo J, Anzueto A, et al. Evaluation of COPD longitudinally to identify predictive surrogate endpoints (ECLIPSE) investigators. Susceptibility to exacerbation in chronic obstructive pulmonary disease. N Engl J Med. 2010;363(12):1128-1138.

77. Gershon A, Croxford R, Calzavara A, et al. Cardiovascular safety of inhaled long-acting bronchodilators in individuals with chronic obstructive pulmonary disease. JAMA Intern Med. 2013;173(13): $1175-1185$.

78. Decramer ML, Chapman KR, Dahl R, et al. Once-daily indacaterol versus tiotropium for patients with severe chronic obstructive pulmonary disease (INVIGORATE): a randomised, blinded, parallel-group study. Lancet Respir Med. 2013;1:524-533.

79. Cowan DC, Cowan JO, Palmay R, et al. Effects of steroid therapy on inflammatory cell subtypes in asthma. Thorax. 2010;65(5):384-390.

80. Hanania NA, Crater GD, Morris AN, et al. Benefits of adding fluticasone propionate/salmeterol to tiotropium in moderate to severe COPD. Respir Med. 2012;106(1):91-101

81. Singh D, Brooks J, Hagan G, Cahn A, O’Connor BJ. Superiority of 'triple' therapy with salmeterol/fluticasone propionate and tiotropium bromide versus individual components in moderate to severe COPD. Thorax. 2008;63:592-598.

82. Welte T, Miravitlles M, Hernandez P, et al. Efficacy and tolerability of budesonide/formoterol added to tiotropium in patients with chronic obstructive pulmonary disease. Am J Respir Crit Care Med. 2009;180:741-750.

83. Saha S, Brightling CE. Eosinophilic airway inflammation in COPD. Int J Chron Obstruct Pulmon Dis. 2006;1(1):39-47.
International Journal of COPD

\section{Publish your work in this journal}

The International Journal of COPD is an international, peer-reviewed journal of therapeutics and pharmacology focusing on concise rapid reporting of clinical studies and reviews in COPD. Special focus is given to the pathophysiological processes underlying the disease, intervention programs, patient focused education, and self management protocols.

\section{Dovepress}

This journal is indexed on PubMed Central, MedLine and CAS. The manuscript management system is completely online and includes a very quick and fair peer-review system, which is all easy to use. Visit http://www.dovepress.com/testimonials.php to read real quotes from published authors. 